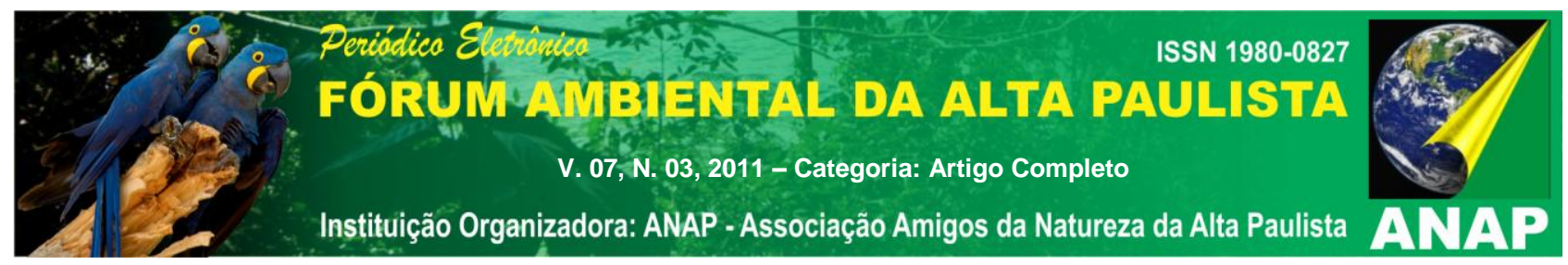

\title{
DISTRIBUIÇÃO ESPACIAL E TEMPORAL DE OVOS E LARVAS DE PEIXES NO RIO AGUAPEÍ SP, ALTO RIO PARANÁ
}

\author{
Patrícia Sarai da Silva ${ }^{1}$ \\ Lucileine de Assumpção ${ }^{2}$ \\ Ariane Furtado de Lima $^{3}$ \\ Maristela Cavicchioli Makrakis ${ }^{4}$ \\ Sergio Makrakis ${ }^{5}$ \\ João Henrique Pinheiro Dias ${ }^{6}$
}

Resumo: Este estudo teve como o objetivo avaliar a ocorrência e distribuição espacial e temporal de ovos e larvas de peixes, bem como, verificar a composição e estratégias reprodutivas das espécies ao longo do rio Aguapeí - SP. As coletas foram realizadas mensalmente de outubro/2009 a março/2010, através de arrastos horizontais na superfície da água durante 10 minutos ao anoitecer utilizando rede de plâncton cônicocilíndrica de $0,5 \mathrm{~mm}$ de malha. Diferenças significativas na densidade média do ictioplâncton entre os locais e meses foram averiguadas através da Análise de Variância Unifatorial (ANOVA one-way). Um total de 1.626 ovos e 1.547 larvas foram coletados. A ANOVA aplicada não demonstrou diferenças significativas nas densidades do ictioplâncton em relação aos pontos amostrados. Com relação a distribuição temporal diferenças significativas $\mathrm{p}<0,05$ foram constatadas para a densidade de ovos e larvas ,com pico na densidade média de ambos em novembro. Trinta e três táxons de larvas foram identificados, com

\footnotetext{
${ }^{1}$ Grupo de Pesquisa em Tecnologia de Produção e Conservação de Recursos Pesqueiros e Hídricos GETECH - UNIOESTE. Toledo, PR. saraipatricia@gmail.com

${ }^{2}$ Grupo de Pesquisa em Tecnologia de Produção e Conservação de Recursos Pesqueiros e Hídricos GETECH - Toledo, PR. lucileinea@hotmail.com

3 Bolsista Capes- Programa de Pós-Graduação em Engenharia de Pesca e Recursos PesqueirosUNIOESTE-Toledo, PR. Arianef_lima@hotmail.com

${ }^{4}$ Grupo de Pesquisa em Tecnologia de Produção e Conservação de Recursos Pesqueiros e Hídricos GETECH - Universidade Estadual do Oeste do Paraná - UNIOESTE. Rua da Faculdade, CEP: 85903-000, Toledo,PR.mmakrakis@terra.com.br

${ }^{5}$ Grupo de Pesquisa em Tecnologia de Produção e Conservação de Recursos Pesqueiros e Hídricos GETECH - Universidade Estadual do Oeste do Paraná - UNIOESTE. Rua da Faculdade, CEP: 85903-000, Toledo,PR.makrakis@terra.com.br

${ }^{6}$ Companhia Energética de São Paulo - CESP. Rodovia Marechal Rondon, km 662. 16920-000. Castilho, SP. joão.dias@cesp.com.br
} 


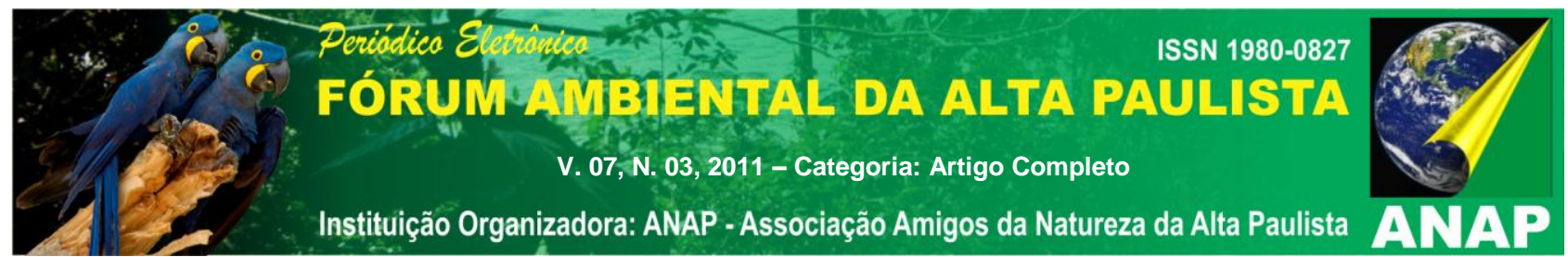

ocorrência de espécies com diferentes estratégias reprodutivas. As larvas da família Anostomidae foram as mais abundantes, porém, destacaram-se a ocorrência de quatro espécies migradoras de longa distância (Prochilodus lineatus, Hemisorubim platyrhynchos/Pseudoplatystoma corruscans, Pimelodus maculatus $e$ Sorubim lima). Os resultados obtidos neste trabalho demonstram a importância do rio Aguapeí como área de desova de várias espécies de peixes, sendo importante a preservação destas áreas de desova a fim de manter as populações de peixes do rio Paraná.

Palavras chaves: áreas de desova, reprodução, ictioplâncton

\section{INTRODUÇÃO}

Um dos eventos mais importantes no ciclo de vida das espécies é a reprodução (KING, 1995), visto que a perpetuação das espécies depende desse processo (LAGLER et al., 1962). Para muitas espécies a reprodução está relacionada às inundações (BEDNARSKI et al., 2008), as quais desempenham um papel importante na vida dos peixes (HUMPHRIES et al., 2002), pois propiciam a formações de novos habitats e disponibilizam maior quantidade de alimento (LOWE-MCCONNELL,1987; JUNK et al., 1989), além de aumentarem a conexão entre os diversos habitats, favorecendo a dispersão dos organismos (THOMAZ et al., 2007).

Os grandes represamentos ao longo do alto rio Paraná têm ocasionado severos impactos sobre as comunidades de peixes, especialmente para as espécies migradoras de longa distância, que podem sofrer intercepção das rotas de migração, redução dos hábitats de desova e criadouros naturais, além do controle do regime hidrológico (WELCOMME, 1979; AGOSTINHO et al., 2007). Com a fragmentação das rotas migratórias das espécies de peixes pelo barramento, os tributários passam a desempenhar papel importante na manutenção das espécies, pois podem atuar como rotas de migração alternativa (BAUMGARTNER et al., 2004).

O rio Aguapeí é um tributário do reservatório de Porto Primavera que pode ser importante para a reprodução das espécies de peixes, especialmente as migradoras de longa distância, se comprovada sua reprodução nesse rio. Os estudos de ovos e larvas de peixes fornecem evidências sobre a ocorrência, local e a época da reprodução das espécies, informações necessárias para a tomada de decisão a respeito das medidas de manejo (NAKATANI et al., 2001), pois auxiliam no planejamento e execução das medidas 


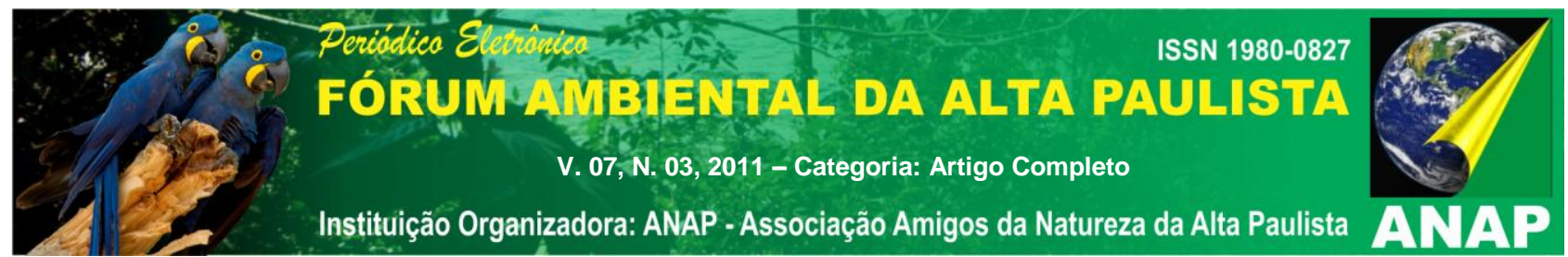

de proteção das áreas de reprodução e berçários, e também a identificar áreas críticas para a conservação das espécies (BAUMGARTNER et al. 2004). Dessa forma, o objetivo deste trabalho foi avaliar a ocorrência e distribuição espacial e temporal de ovos e larvas de peixes, bem como, verificar a composição e estratégias reprodutivas das espécies ao longo do rio Aguapeí - SP.

\section{MATERIAIS E METÓDOS}

\subsection{Caracterização da área de estudo}

A área de estudo compreendeu o rio Aguapeí, um dos tributários do reservatório de Porto Primavera, rio Paraná-SP/MS. O rio Aguapeí (Figura 1), encontra-se na margem esquerda do rio Paraná, correndo do sudeste para o noroeste, com $305 \mathrm{~km}$ de curso (PAIVA, 1982). Localizado no Estado de São Paulo, caracteriza-se por apresentar um padrão meândrico em todo o seu curso, ser estreito e de pouca profundidade, apresentar valores elevados de condutividade e turbidez. Ao longo de todo o curso são observadas várias lagoas marginais e suas margens são cobertas por vegetação arbustiva e arbórea. O trecho de amostragem abrangeu aproximadamente $30 \mathrm{~km}$ no sentido da foz a montante, com amostragens em cinco pontos, compreendendo tanto trechos lóticos como também uma lagoa marginal (conhecida como Lagoa Pau da Onça), com conexão permanente com o rio. Essa lagoa apresenta uma área de aproximadamente 2,0 hectares, com mata ciliar preservada (CESP, 2006). 

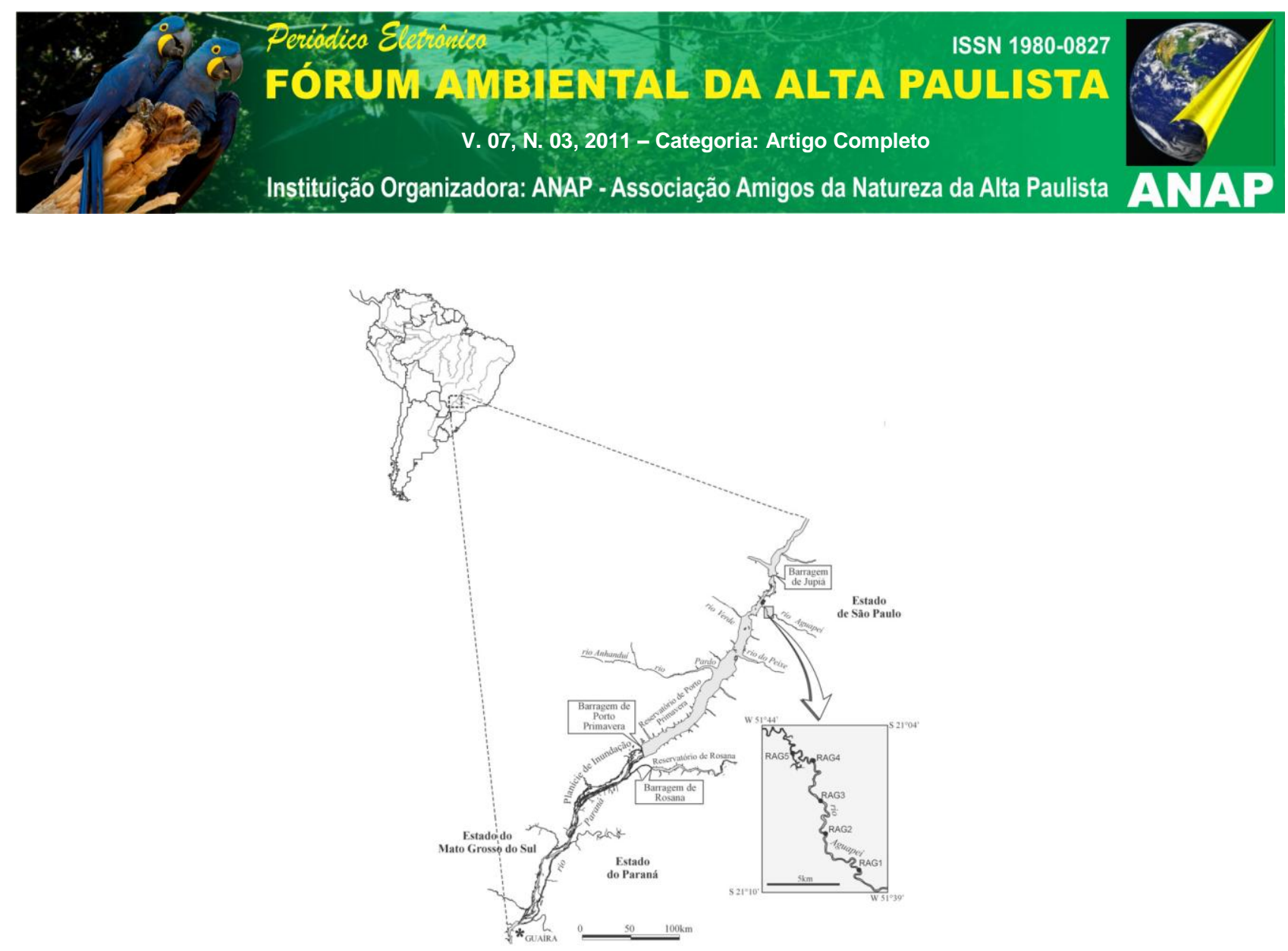

Figura 1. Área de estudo: localização das estações de amostragens no rio Aguapeí, SP.

\subsection{Coleta de dados}

Para este estudo foram utilizados dados provenientes de coletas realizadas em cinco pontos de amostragem: quatro no canal do rio Aguapeí (RAG1, RAG2, RAG3, RAG4) e um na lagoa marginal localizada a margem esquerda do rio Aguapeí (RAG5) entre os meses de outubro de 2009 a março de 2010.

As amostras de ovos e larvas de peixes foram obtidas através de arrastos horizontais durante 10 minutos ao anoitecer utilizando-se redes de planctôn do tipo cônico-cilíndrica (malha $0,5 \mathrm{~mm}$ ) com um fluxômetro acoplado a boca da rede para a determinação do volume de água filtrada.

Inicialmente as amostras foram submetidas a eutanasia com benzocaína (concentração de $250 \mathrm{mg} / \mathrm{l}$, por pelo menos 10 minutos de exposição), em seguida as amostras foram fixadas em formol $4 \%$ tamponado com cabornato de cálcio $\left(\mathrm{CaCO}_{3}\right)$.

No laboratório, procedeu-se a triagem das amostras, utilizando para isso placas de acrílico do tipo Bogorov sob um microscópio estereoscópico. A identificação das larvas de peixes foi realizada até o menor nível taxonômico possível, seguindo Nakatani et al. 


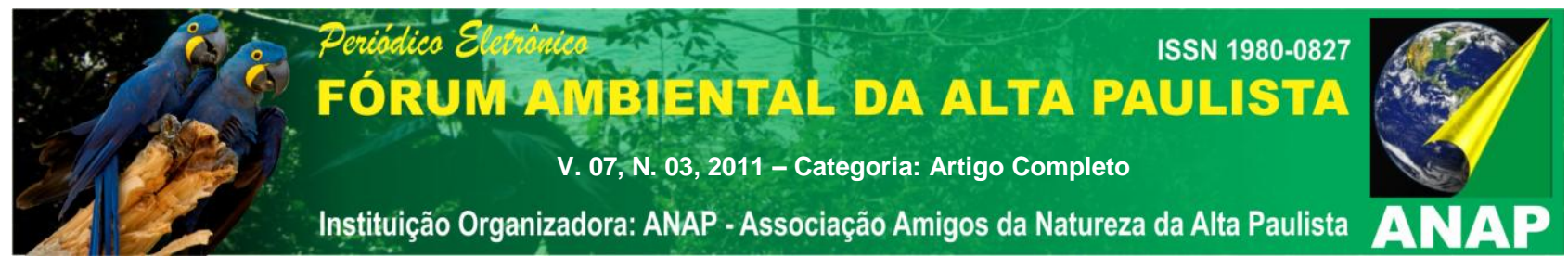

(2001) e Graça \& Pavanelli (2007). As estratégias reprodutivas das espécies foram determinadas seguindo Agostinho et al. (2003, 2007) e Suzuki et al. (2004): MIG= migradoras longa distância; $\mathrm{SSC}=$ sedentárias sem cuidado parental; $\mathrm{SCC}=$ sedentárias com cuidado parental; SFIE= sedentárias com fecundação interna e desenvolvimento externo. Para as espécies sem informações disponíveis na literatura, foi adotada a sigla NC.

\subsection{Análise de dados}

Diferenças na densidade média do ictioplâncton entre os locais e meses de amostragens foram verificadas através da Análise de Variância Unifatorial (One-Way ANOVA), considerando os diferentes locais e meses como fatores independentes. As densidades médias de ovos e larvas foram transformadas em $\log 10(x+1)$ para atingir os pressupostos de normalidade e homogeneidade da variância (PETERS, 1986). Quando diferenças significativas $(p<0,05)$ foram verificadas pela One - Way Anova, o teste a posteriori de Tukey foi aplicado. O software STATISTICA v. 7. 0 foi utilizado nesta análise.

\section{RESULTADOS}

3.1 Ocorrência e Distribuição Espacial e Temporal

As amostragens realizadas no rio Aguapeí resultaram na captura de 1.626 ovos e 1.547 larvas, com ocorrência de ambos em todos os pontos de amostragens. A ANOVA aplicada não demonstrou diferenças significativas $(p>0,05)$ nas densidades de ovos (ANOVA, $F=0,51 ; p=0,72$ ) e larvas (ANOVA, $F=0,18 ; p=0,94$ ) entre os pontos de amostragens. Entretanto, as densidades médias de ovos foram mais elevadas no RAG4 (Figura 2), e as de larvas no RAG5 (Figura 2). 

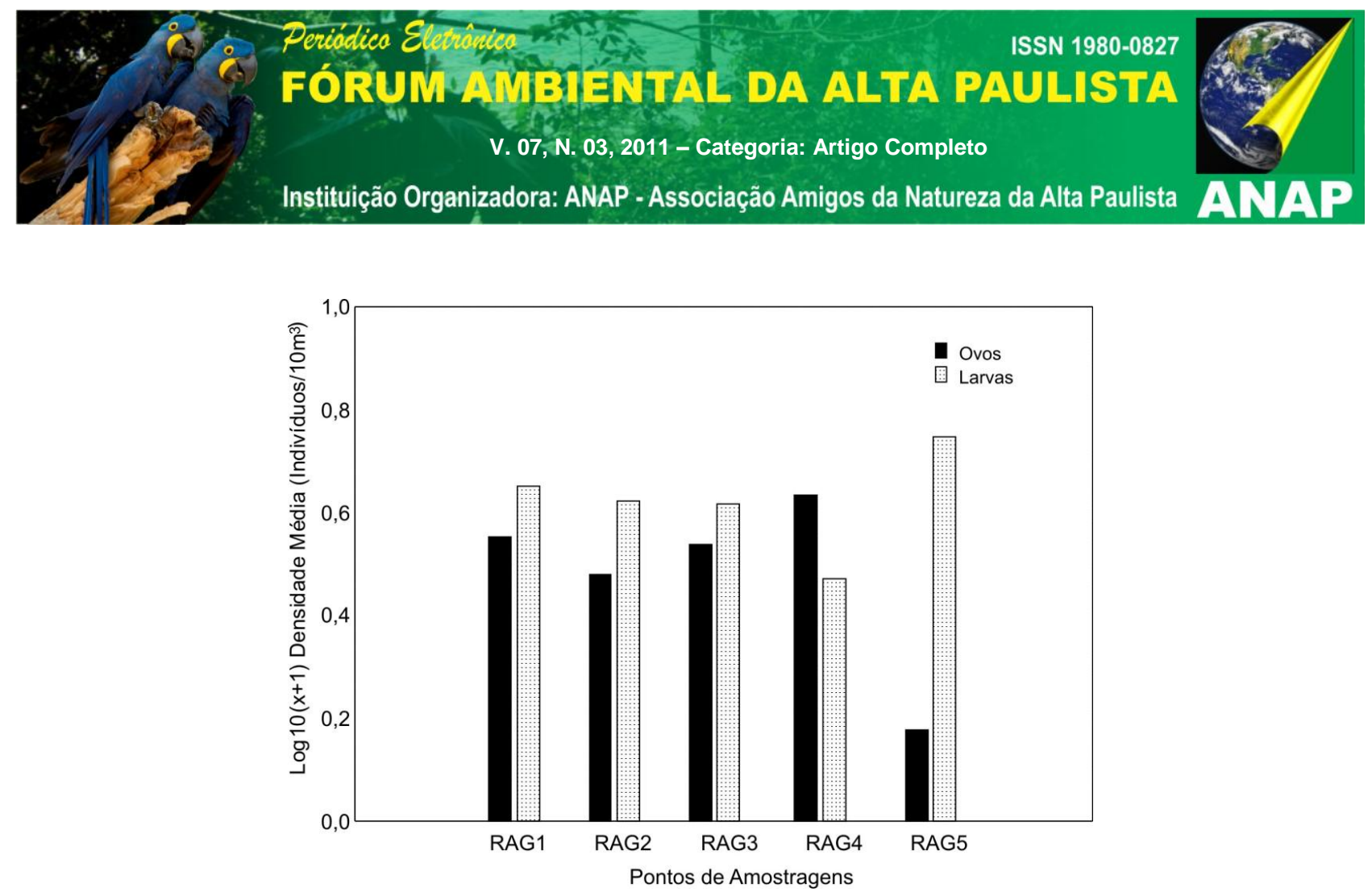

Figura 2 - Densidade média de ovos e larvas de peixes capturados nos diferentes pontos de amostragens do rio Aguapeí (RAG), no período de outubro de 2009 a março de 2010.

Diferenças significativas foram averiguadas para a densidade de ovos (ANOVA, $F=7,10 ; p=0,0003$ ) e larvas (ANOVA, $F=11,16 ; p<0,00001$ ) em relação aos meses de amostragens, com pico na densidade média desses organismos em novembro (Teste de Tukey, $p<0,05$ ) (Figura 3).

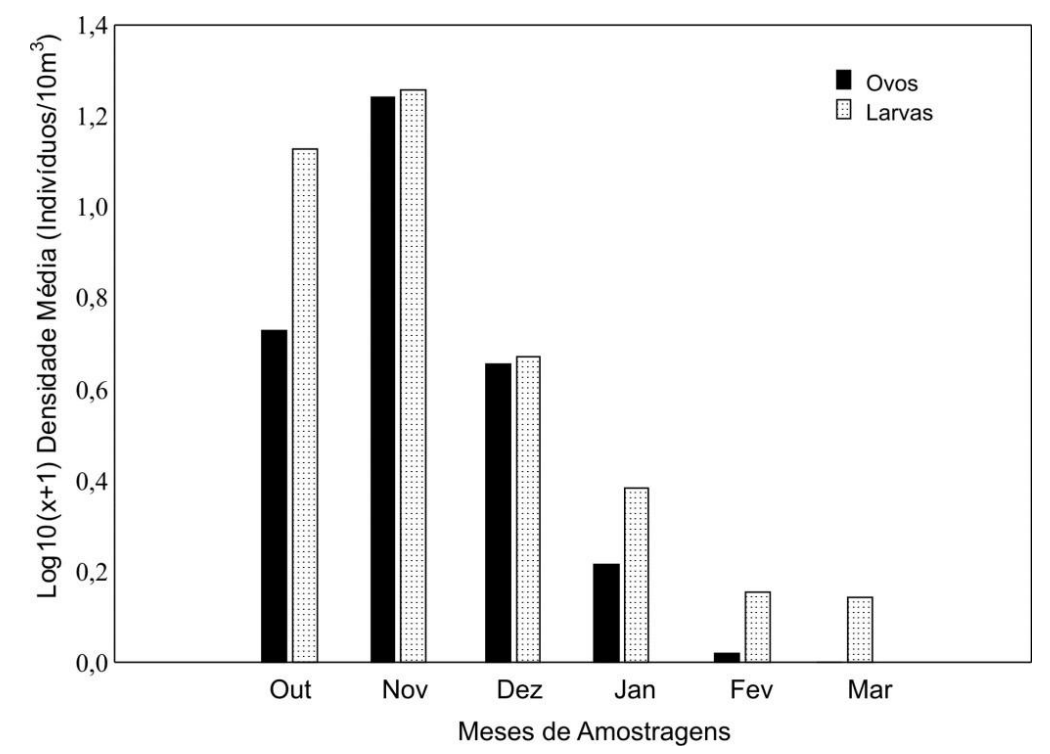




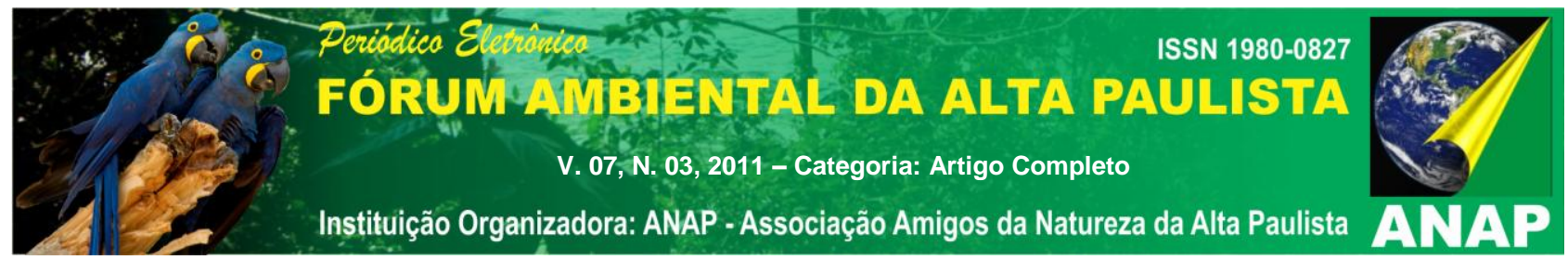

Figura 3 - Distribuição mensal da densidade média de ovos e larvas de peixes capturados no rio Aguapeí, no período de outubro de 2009 a março de 2010.

\subsection{Composição Taxonômica e Estratégias reprodutivas}

A composição das espécies foi constituída por 33 grupos taxonômicos, sendo representado por espécies com diferentes estratégias reprodutivas (Tabela 1). As ordens Characiformes (16) e Siluriformes (15) apresentaram o maior número de táxons identificados. A família Characidae foi a mais numerosa sendo representadas por 10 táxons (Tabela 1).

As maiores densidades de larvas foram registradas para a família Anostomidae $\left(2,11\right.$ larvas $\left./ 10 \mathrm{~m}^{3}\right)$, com capturas em todos os pontos de amostragens e maiores densidades no RAG5 (5,02 larvas $\left./ 10 m^{3}\right)$ (Tabela 1). As larvas de $H$. platyrhynchos/P. corruscans também apresentaram densidades elevadas (Tabela 1). As espécies (Hemisorubim platyrhynchos e Pseudoplatystoma corruscans) possuem grande similaridade morfológica quando estão no início do desenvolvimento larval (larval vitelino e pré-flexão) e, por isso, estas espécies nestes estágios foram referidas como $H$. platyrhynchos /P. corruscans e tratadas como um táxon distinto dos demais.

As espécies de larvas migradoras de longa distância estiveram representadas por quatro espécies, Prochilodus lineatus, $H$. platyrhynchos/P. corruscans, Pimelodus maculatus e Sorubim lima (Tabela 1). Essas espécies ocorreram apenas em trecho lótico (RAG1 a RAG4) não sendo verificada a ocorrência dessas na lagoa (RAG5) (Tabela 1). 


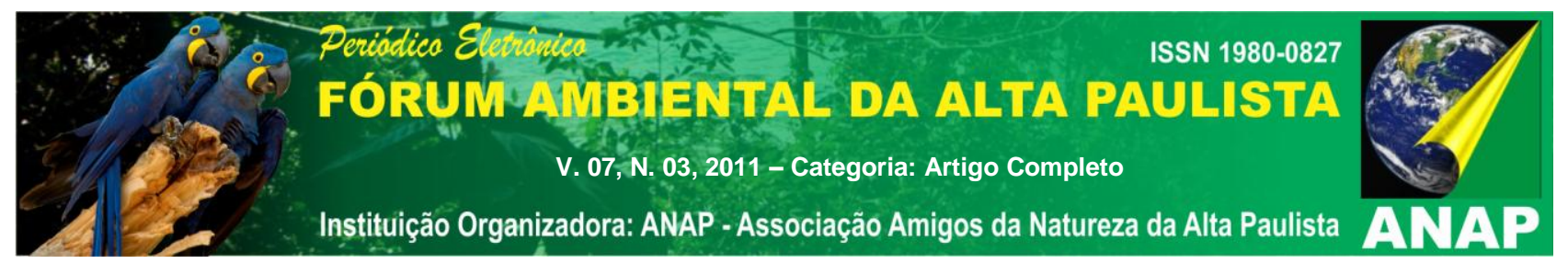

Tabela 1 - Estratégias reprodutivas (E.R) e densidade média das larvas $/ 10 \mathrm{~m}^{3}$ capturadas nos pontos de amostragens do rio Aguapeí. SSC= Sedentárias sem cuidado parental, $\mathrm{SCC}=$ Sedentárias com cuidado parental, $\mathrm{SFIE}=$ Sedentárias com fecundação interna e desenvolvimento externo, $\mathrm{MIG}=$ migradoras de longa distância, SSC/SCC= espécies não identificadas ao nível específico podendo, pelo gênero, sendentárias sem cuidado parental ou sedentárias com cuidado parental, SSC/MIG espécies não identificadas ao nível específico podendo, serem Sedentárias sem cuidado parental ou migradoras de longa distância NC=não conhecida.

\begin{tabular}{|c|c|c|c|c|c|c|}
\hline Grupos Taxonômicos & E.R & RAG1 & RAG2 & RAG3 & RAG4 & RAG5 \\
\hline Prochilodus lineatus (Valenciennes, 1836) “curimba”, "curimbatá" & MIG & 0,97 & - & - & 1,00 & - \\
\hline Família Anostomidae & & 1,04 & 0,46 & 2,89 & 1,17 & 5,03 \\
\hline Família Characidae & & - & - & - & - & 0,08 \\
\hline Astyanax spp. - "tambiú" & SSC & 0,02 & 0,02 & - & 0,02 & - \\
\hline Bryconamericus spp. - "piquira" & SSC & 0,06 & - & - & - & 0,12 \\
\hline $\begin{array}{l}\text { Serrasalmus spp. "piranha" } \\
\text { Subfamília Aphyocharacinae }\end{array}$ & SCC & 0,04 & 0,07 & 0,11 & 0,02 & 0,14 \\
\hline $\begin{array}{l}\text { Aphyocharax spp. "piquira" } \\
\text { Subfamília Characinae }\end{array}$ & SSC & - & & - & - & 0,02 \\
\hline $\begin{array}{l}\text { Roeboides descalvadensis Fowler, } 1932 \text {-"dentudo", "lambiá" } \\
\text { Subfamília Cheirodontinae }\end{array}$ & SSC & - & - & - & - & 0,27 \\
\hline
\end{tabular}




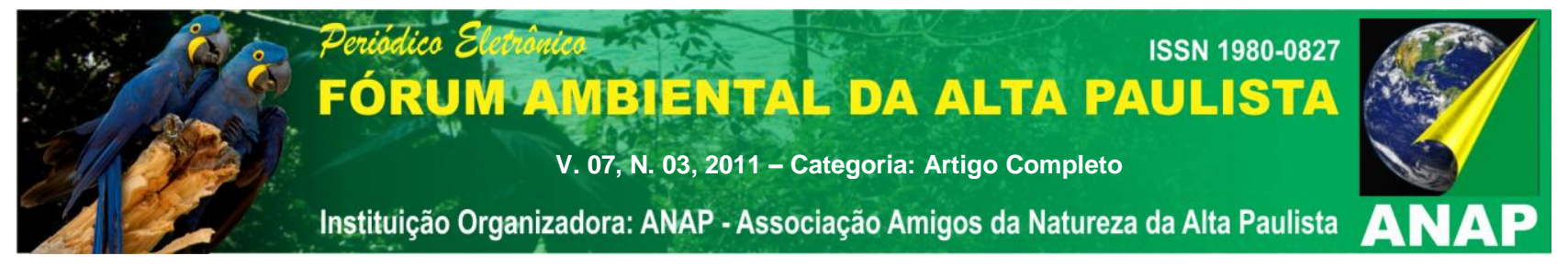

Hoplias spp. "traíra", "lobó"

SCC

0,12

0,29

0,36

0,09

0,35 


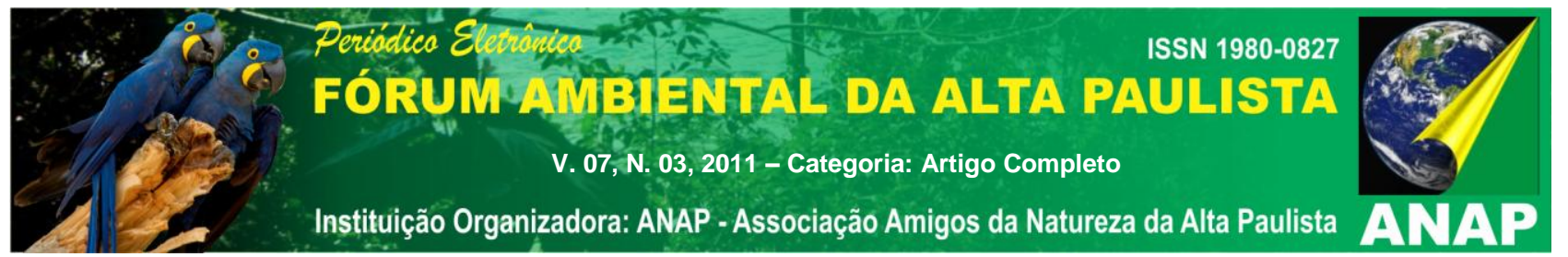

Continuação Tabela 1.

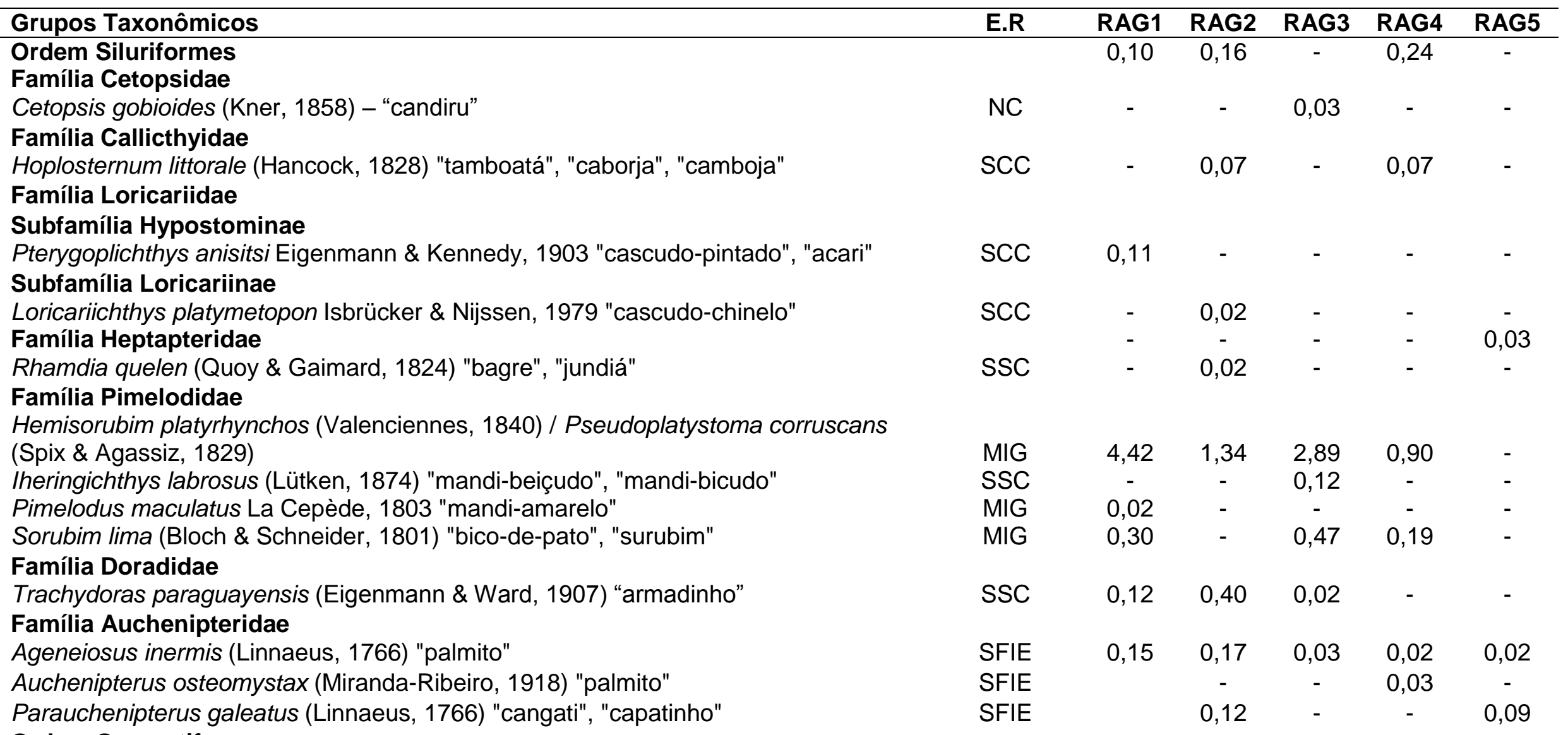




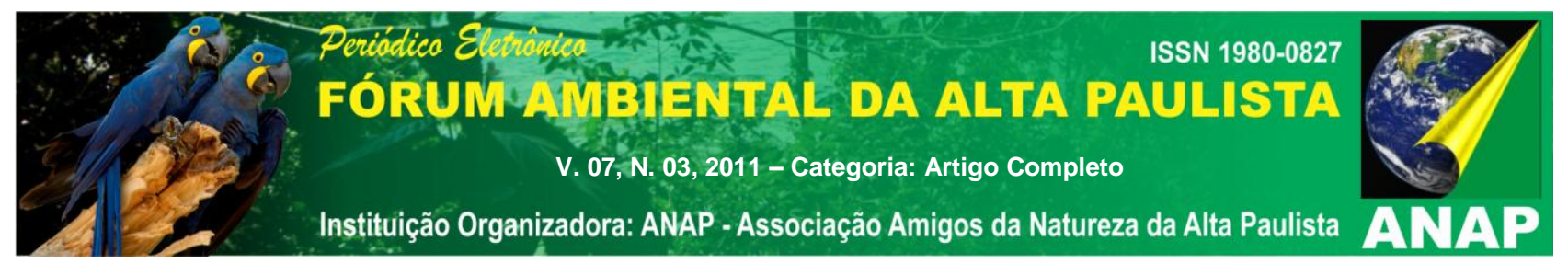

\section{Família Gymnotidae}

Gymnotus spp. "morenita, tuvira"

Família Sternopygidae

SSC/SCC

0,06

0,08

0,03

0,06

Eigenmannia spp. "espadinha"

SSC

0,09

0,25

0,11

0,09 


\section{DISCUSSÃO}

\subsection{Ocorrência e Distribuição Espacial e Temporal}

A ocorrência de ovos e larvas ao longo do trecho amostrado do rio Aguapeí demonstra a importância desse rio como área de desova de várias espécies de peixes, que tem encontrado condições propícias para efetuarem sua reprodução e provavelmente seu desenvolvimento inicial. A ausência de diferenças significativas na densidade de ovos e larvas entre os pontos de amostragens comprova que a reprodução tem ocorrido em todo trecho amostrado. Estudos realizados em alguns rios da planície de inundação do Alto rio Paraná têm relatado a existência de um gradiente longitudinal, sendo os ovos mais abundantes nas cabeceiras dos rios, diminuindo mais próximo da foz (NAKATANI et al., 1997; BAUMGARTNER et al., 2004).

Embora diferenças significativas não tenham sido detectadas na distribuição de larvas entre os pontos de amostragens, notam-se maiores densidades de larvas para o RAG5 (lagoa), mesmo com número superior de pontos de amostragens no canal do rio, sugerindo que algumas espécies têm utilizado preferencialmente o RAG5 (lagoa) para efetuar seu desenvolvimento inicial. As lagoas, por serem criadouros naturais, fornecem alimento apropriado e abrigo, tornando possível o desenvolvimento das espécies (SMITH \& BARRELLA, 2000), suprindo as necessidades biológicas e ecológicas das populações (CUNICO et al., 2002), são tidas como berçários naturais, favorecendo a reprodução e desenvolvimento do ciclo de vida das espécies sedentárias, e também o desenvolvimento das espécies migradoras de longa distância (AGOSTINHO et al., 2007).

Quanto à distribuição temporal, observamos que a reprodução ocorreu principalmente entre os meses de outubro à dezembro. Esses resultados se encontram dentro do padrão proposto por Vazzoler (1996) para a maioria dos peixes da planície do alto rio Paraná; essa autora menciona maior atividade reprodutiva das espécies entre novembro e janeiro. Por outro lado, o pico de ovos e larvas em novembro, evidenciando que a reprodução das espécies no rio Aguapeí ocorreu, 
sobretudo nesse mês. Em ambientes tropicais a desova apresenta uma periodicidade sazonal, que está relacionada a fatores ambientais (WELCOMME, 1979; BAUMGARTNER et al., 2005). Segundo Bailly et al. (2008) os picos da reprodução antecedem os picos das cheias, independentemente da estratégia reprodutiva.

\subsection{Composição Taxonômica e Estratégias reprodutivas}

As larvas encontradas neste estudo são principalmente representantes da família Characidae, e sedentárias sem cuidado parental. Um aspecto que contribuiu para isso foram as amostragens realizadas na lagoa (RAG5), já que, naquele ponto houve predomínio das larvas pertencentes à essa família. As espécies sedentárias são comuns em ambientes lênticos (AGOSTINHO et al., 2007; GODINHO et al., 2009). Elas apresentam maturação rápida, período reprodutivo prolongado, alta fecundidade e ovos pequenos (SUZUKI et al., 2005).

As capturas elevadas de larvas de Anostomidae indicam que essa família encontra, nesse rio, locais propícios para efetuar sua reprodução e possivelmente para completar todo o seu desenvolvimento inicial, já que larvas dessa família foram encontradas em diferentes estágios de desenvolvimento. Muitos estudos têm relatado a importância de grandes tributários para a reprodução das espécies e especialmente para as migradoras de longa distância, quando da existência de reservatórios e principalmente com a construção desses em cascatas, em função das espécies utilizá-los como rotas alternativas (CORRÊA et al., 2011; HERMESSILVA et al., 2009; BAUMGARTNER et al., 2004). A presença das espécies migradoras de longa distância (Prochilodus lineatus, H. platyrhynchos/P. corruscans, Pimelodus maculatus e Sorubim lima) no rio Aguapeí, explana a adequabilidade do trecho amostrado em termos disponibilidade de habitats apropriados para a reprodução e possível desenvolvimento inicial dessas espécies. A ausência de larvas de espécies migradoras de longa distância na lagoa sugere que essas 
espécies têm se reproduzido apenas no canal do rio Aguapeí. As espécies migradoras de longa distância desovam em correnteza, se posicionam acima dos locais usados como berçários e a prole produzida deriva rio abaixo até atingirem as áreas berçários (FUIMAN \& WERNER, 2002) como lagoas marginais, baías e ambientes de várzea onde completam seu desenvolvimento (KING, 1995; AGOSTINHO et al., 2007).

\section{CONCLUSÃO}

Este estudo demonstrou que não existe variação significativa na densidade de ovos e larvas em relação aos diferentes pontos de amostragens no rio Aguapeí. Em relação à distribuição temporal notamos que as desovas ocorreram principalmente em novembro. A composição taxonômica foi formada por espécies com diferentes estratégias reprodutivas, incluindo algumas espécies migradoras de longa distância. A presença das espécies migradoras de longa distância no rio Aguapeí demonstra a importância deste tributário como área de desova, havendo a necessidade de se preservar essas áreas a fim de assegurar a manutenção do estoque pesqueiro dessas espécies inclusive no reservatório de Porto Primavera.

\section{REFERÊNCIAS}

AGOSTINHO, A. A. et al. Migratory fishes of the upper Paraná River basin, Brazil. Pp. 19-89. In: CAROLSFELD, J. et al. (Eds.). Migratory fishes of South America: Biology, Fisheries and Conservation Status. Washington: World Bank. 2003. $372 \mathrm{p}$.

AGOSTINHO, A. A.; GOMES, L. C. \& PELICICE, F. M. Ecologia e Manejo de Recursos Pesqueiros em Reservatórios do Brasil. Maringá: Eduem. 2007. 507p.

BAUMGARTNER, G. et al. Identification of spawning sites and natural nurseries of fishes in the upper Paraná River, Brazil, Environmental Biology of Fishes, v.71, p. 115-125, 2004. 
BAUMGARTNER, G. et al. Variação nas densidades de larvas de peixes durante vários períodos de desova, no reservatório de Itaipu. In: XVIII Seminário Nacional de Produção e Transmissão de Energia Elétrica, Curitiba, XVIII SNPTEE. 2005.

BAUMGARTNER, G. et al. Fish larvae from the upper Paraná River: do abiotic factors affect larval density? Neotropical Ichthyology, v.6, n.4, p. 551-558, 2008.

BEDNARSKI, J.; MILLER, S. E. \& SCARNECCHIA, D. L. Larval fish catches in the lower Milk River, Montana in relation to timing and magnitude of spring discharge. River Research and Applications, v.24, p. 844-851, 2008.

COMPANHIA ENERGÉTICA DE SÃO PAULO - CESP - UHE Sergio Motta Programa de monitoramento da ictiofauna e dos recursos pesqueiros, 2006. Levantamento de ovos e Larvas de peixes e reprodução - Relatório OA/031/2006.

CORRÊA, R. et al. Distribution and abundance of fish eggs and larvae in three tributaries of the Upper Uruguay River (Brazil). Environmental Biology of Fishes, v.91, p.51-61, 2010.

CUNICO, M. A. et al. Influência do nível hidrológico sobre a assembléia de peixes em sazonalmente isolada da planície de inundação do alto rio Paraná. Acta Scientiarum, v.24, p. 383-389, 2002.

FUIMAN, L. A. \& WERNER, R. G. Fishery science: the unique contributions of early life stages. Oxford: Blackwell Science. 2002. 396p.

HERMES - SILVA, S.; REYNALTE - TATAJE, D. \& ZANIBONI-FILHO, E. Spatial and Temporal Distribution of Ichthyoplankton in the upper Uruguay River, Brazil. Brazilian Archives of Biology and Technology, v.52, n.4, p. 933-944, 2009.

HUMPHRIES, P.; SERAFINI. L. G. \& KING, A. J. River regulation and fish larvae: variation through space and time. Freshwater Biology, v.47, n.7, p.1307-1331, 2002.

GODINHO, A. L.; LAMAS, I. R. \& GODINHO, H. P. Reproductive ecology of Brazilian freshwater fishes. Environmental Biology of Fishes, v.87, p.143-162, 2009.

GOMES, L. C. \& AGOSTINHO, A. A. Influence of the flooding regime on the nutritional state and juvenile recruitment of the curimbá, Prochilodus scrofa, Steindachner, in Upper Paraná River, Brazil. Fisheries Management and Ecology, v.4, n.4, p. 263-274, 1997.

GRAÇA, W. J. \& PAVANELLI, C. S. Peixes da planície de inundação do alto rio Paraná e áreas adjacentes. Maringá: Eduem. 2007. 241p. 
JIMÉNEZ - SEGURA, L. F., PALACIO J. \& LEITE, R. River flooding and reproduction of migratory fish species in the Magdalena River basin, Colombia. Ecology of Freshwater Fish, v.19, p.178-186, 2010.

JUNK, W.J.; BAYLEY, P. B. \& SPARKS, R. E. 1989. The flood pulse concept in riverfloodplain systems. Pp. 110-127. In: DODGE, D.P. (Ed). Proceedings of the International Large River Symposium, Canadian Special Publication of Fisheries and Aquatic Sciences. 106.

KING, M. G. Fisheries Biology, Assessment and Management. England: Fishing News Books. 1995. 341p.

LAGLER, K. F.; BARDACH, J. E. \& MILLER, R. R. Ichthyology. New York: John Willey. 1962. 506p.

LOWE-MCCONNEL, R. H. 1987. Ecological studies in tropical fish communities. Cambridge: Cambridge University Press, 382p.

NAKATANI, K.; BAUMGARTNER, G. \& CAVICCHIOLI, M. Ecologia de ovos e larvas de peixes. pp. 281-306. In: VAZZOLER, A. E. A. M.; AGOSTINHO, A. A. \& HAHN, N. $S$. (Ed). A planície de inundação do alto rio Paraná: aspectos físicos, biológicos e socioeconômicos: Maringá, EDUEM. 1997.

NAKATANI, K.et al. Manual de identificação de ovos e larvas de peixes brasileiros de água doce: Maringá, EDUEM. 2001. 378p.

PAIVA, M. P. Grandes represas do Brasil. Brasília: Editerra. 1982. 302p.

PELICICE, F. M. \& AGOSTINHO, A. A. Fish - Passage Facilities as Ecological Traps in Large Neotropical Rivers. Conservation Biology, v.22, p.180-188, 2008.

PETERS, R. K. The role of prediction in limnology. Limnology and Oceanography, v.31, n.5, p. 1143-1159, 1986.

SMITH, W.S. \& W. BARRELLA. The ichthyofauna of the marginal lagoons of the Sorocaba River, SP, Brazil: composition, abundance and effect of the anthropogenic actions. Revista Brasileira de Biologia, v.60, n.4, p. 627-632, 2000.

SUZUKI, H. I. et al. Reproductive ecology of the fish assemblages. Pp. 271-292. In: THOMAZ, S. M.; AGOSTINHO, A. A.; HAHN, N. S. (Ed.). Upper Paraná River and its Floodplain: physical aspects, ecology and conservation. Leiden, The Netherlands: Backhuys Publishers. 2004. 393p.

SUZUKI, H. I.; BULLA, C. K. \& AGOSTINHO, A. A. Estratégias reprodutivas de assembléias de peixes em reservatórios. Pp.223-236. In: RODRIGUES, L.; 


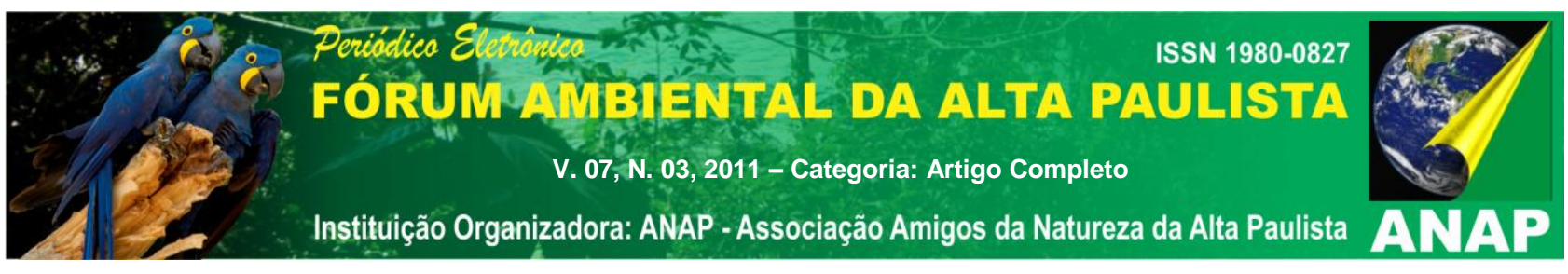

THOMAZ, S. M.; AGOSTINHO, A. A. \& GOMES, L. C. (Eds). Biocenoses em reservatórios Padrões espaciais e temporais. São Carlos: RiMa. 2005. 333p.

THOMAZ S. M, L. M. BINI \& R. L BOZELLI. Flood increase similarity among aquatic habitat in river - floodplain systems. Hydrobiologia, v.579, p.1-13, 2007.

VAZZOLER, A. E. A. M. Biologia da reprodução de peixes teleósteos: teoria e prática. Maringá: Eduem. 1996. 169p.

WELCOMME, R. L. Fisheries ecology of floodplain rivers. New York: Longman.1979. 317p. 